\title{
Development of Nitrocellulose-based Propellants With Natural Stabilizers
}

\author{
Rodrigo Leonard Barboza Rodrigues ${ }^{1, *}$, Maurício Ferrapontoff Lemos², Tanos Celmar Costa França ${ }^{1,3}$, \\ Letivan Gonçalvez Mendonça Filho'
}

\author{
Rodrigues RLB (D https: / /orcid.org/0000-0002-7041-583X \\ Lemos MF (iD https://orcid.org/0000-0002-5933-9135 \\ França TCC (D) https://orcid.org/0000-0002-6048-8103 \\ Mendonça Filho LG (D) https: / /orcid.org/0000-0002-3175-8477
}

\author{
How to cite \\ Rodrigues RLB; Lemos MF; França TCC; Mendonça Filho LG \\ (2019) Development of Nitrocellulose-based Propellants with \\ Natural Stabilizers. J Aerosp Technol Manag, 11, Special \\ Edition: 3-6. https://doi.org/10.5028/jatm.etmq.40
}

\begin{abstract}
Traditional stabilizers for nitrocellulose-based (NC-based) propellants are known to have carcinogenic, mutagenic and toxicity to reproduction potentials. Therefore, the replacement of these stabilizers in the propellants formulations is necessary, but with no losses regarding stabilization efficiency and shelf life of propellant. In this context, NC-based propellants were prepared using the natural substances curcumin and guaiacol as stabilizers. The chemical stability of the samples evaluated by a heat-flux microcalorimeter (HFC) suggests that the new propellants are more stable than the traditional ones. Also, a complementary in silico analysis was performed on toxicity prediction software (LAZAR, Toxtree, VEGA and TEST) based on the similarity with substances contained in their databases. The results concluded that curcumin stabilizer presents no toxicity, while guaiacol can have carcinogenic and mutagenic potential.
\end{abstract}

KEYWORDS: Nitrocellulose; Stabilizers; Green propellant; Prediction; Toxicity.

\section{INTRODUCTION}

Nitrocellulose-based (NC-based) propellants become unstable during aging and need stabilizers in order to prevent their autocatalytic degradation process, thus increasing their shelf life. Traditional stabilizers such as diphenylamine (DPA) and ethylcentralite (EC) are very effective on this task, but are also known to generate molecules containing the group $\mathrm{N}-\mathrm{N}=\mathrm{O}$ (N-nitrous) which is potentially carcinogenic, mutagenic and toxic to reproduction (CMR) (Agency for Toxic Substances and Disease Registry 2017).

Green stabilizers, such as curcumin and guaiacol, are proposed as substances that may replace the usual stabilizers without the formation of any long-term detectable number of CMR-derived products (Dobson et al. 2016). Curcumin can be extracted from the roots of turmeric (Curcuma longa) and has been reported (Johnston and DeMaster 2003) as an excellent receptor of $-\mathrm{NO}_{2}$ groups. Guaiacol is a natural substance present in guaco or witch's weed leaves (Mikania glomerata Spreng.) and has been proved to interact with the nitrite present in the atmosphere to produce 4-nitroguaiacol, 6-nitroguaiacol and 4,6-dinitroguaiacol (Kroflic et al. 2015).

The use of computational toxicity prediction tools has enabled safer choices in the development or replacement of substances used in propellant formulation by assessing their toxicological and environmental risks in advance. It is noteworthy that computational toxicology is already widely applied in the pharmaceutical industry (Muster et al. 2008). Some software servers

\footnotetext{
1.Instituto Militar de Engenharia - Departamento de Engenharia Quimica - Rio de Janeiro/RJ - Brazil.

2. Instituto de Pesquisa da Marinha - Grupo de tecnologia de Materiais - Rio de Janeiro/RJ - Brazil.

3.University of Hradec Králové of Science - Department of Chemistry - Hradec Králové - Czech Republic.

*Correspondence author: rodrigo.leonard@hotmail.comr

Received: 27 Nov 2019 | Accepted: 10 Dec 2019

Note: This paper was selected from the 10o Encontro Técnico de Materiais e Química (ETMQ) ocurred in 27-29 november of 2019 and organized by Instituto de Pesquisas da Marinha (IPqM) in Rio de Janeiro/RJ, Brazil
} 
normally used for in silico predictions are the lazy structure-activity relationship (LAZAR) (Helma 2006), Toxtree 3.1.0 (Patlewicz et al. 2008), VEGA 1.1.4 (Benfenati et al. 2013) and the Toxicity Estimation Tool (TEST) (Martin 2016). These softwares are based on the structures of compounds related to the investigated substance in their database, which are the quantitative of structureactivity relationship (QSAR) models. LAZAR uses the OpenTox (Vedani et al. 2015) database, the world's largest open platform for predictive toxicity. Similarities are calculated by the Tanimoto-Jaccard method (Fligner et al. 2002). Toxtree shows selected warnings based on the Benigna-Bossa rule (Benigni et al. 2013). This software uses data from the Danish QSAR database and the EURL ECVAM - Consolidated Reference Laboratory for Animal Testing -, consolidated for genotoxicity and carcinogenicity. VEGA has a library of about 4340 compounds (Helma et al. 2004) and was developed for the CAESAR project - ComputerAssisted Evaluation of Industrial Chemicals (Cassano et al. 2010). TEST uses the mutagenicity database from the Hansen library with about 5740 compounds, according to its user guide (Martin 2016; Hansen et al. 2009).

The authors of this study prepared formulations of new NC-based propellants containing curcumin and guaiacol as natural stabilizers and evaluated their chemical stability through heat flow microcalorimetry (HFC) tests. Also, the possible toxicity (if they have carcinogenic and mutagenic potential) of curcumin and guaiacol were evaluated through the use of the computational toxicity prediction software LAZAR, Toxtree, VEGA and TEST.

\section{METHODOLOGY}

The NC-based propellants samples were produced as a mixture of NC (Nitrochemie Wimmis) using 2 parts of high nitrogen per part of low nitrogen type (mass ratio). After drying the mixture for $48 \mathrm{~h}$, an amount of 1.0 wt.\% of stabilizer (1.5 wt.\% for EC) dissolved in acetone was added. The stabilizers used were DPA and EC (Sigma-Aldrich), curcumin 95.0\% (Vesherb) and guaiacol 99.0\% (Sigma-Aldrich). Acetone (Isofar) was used as solvent for the stabilizer addition, as well as for gelatinization and homogenization.

The HFC model TNO P0810 was used for chemical stability assessment - this technique measures the total heat generated by $5.0 \mathrm{~g}$ of propellant sample. The standards associated with this test are MIL-STD-286C/method 802.1 (DQSO 2010) and STANAG-4582 (NATO 2007). The approval criterion for traditional stabilizers considers that the heat flux output during the test shall remain lower than $201 \mu \mathrm{W} / \mathrm{g}$ at $85^{\circ} \mathrm{C}$.

Similarly to a former work (Rodrigues et al. 2018), the prediction of stabilizers in silico toxicity was performed in the webservers software LAZAR, Toxtree, VEGA and TEST.

\section{RESULTS AND DISCUSSION}

Figure 1 shows a comparison in the HFC stability test between DPA and EC stabilized samples and those with guaiacol and curcumin green stabilizers. The performances of the green stabilizers were superior than the traditional ones, suggesting that there are no losses regarding stabilization efficiency - at least by using HFC test. According to the method reported by Bohn (2009), the maximum heat flow peaks and the total areas below the heating isotherm were lower than the reference sample, suggesting that they may be more stable over time than usual stabilizers.

Table 1 shows the toxicity prediction results through LAZAR, Toxtree, VEGA and TEST software tools for the four stabilizers studied. The output results report whether the similarity calculation model was successful or not in terms of convergence, generating a result with the investigated toxicity suspected to be toxic or nontoxic. In this case, the bold fonts are convergent results in the software applicability domain, while the others only indicate a tendency. By interpreting only the convergent results, all the softwares suggest that guaiacol may have mutagenic and carcinogenic potential, while DPA is mutagenic. On the other hand, curcumin is pointed as nontoxic in all cases. No convergence was found in the results for EC, but some studies already demonstrated the formation of toxic products after the reaction of this stabilizer with nitrous groups from NC decomposition (Curtis and Berry 1989). 


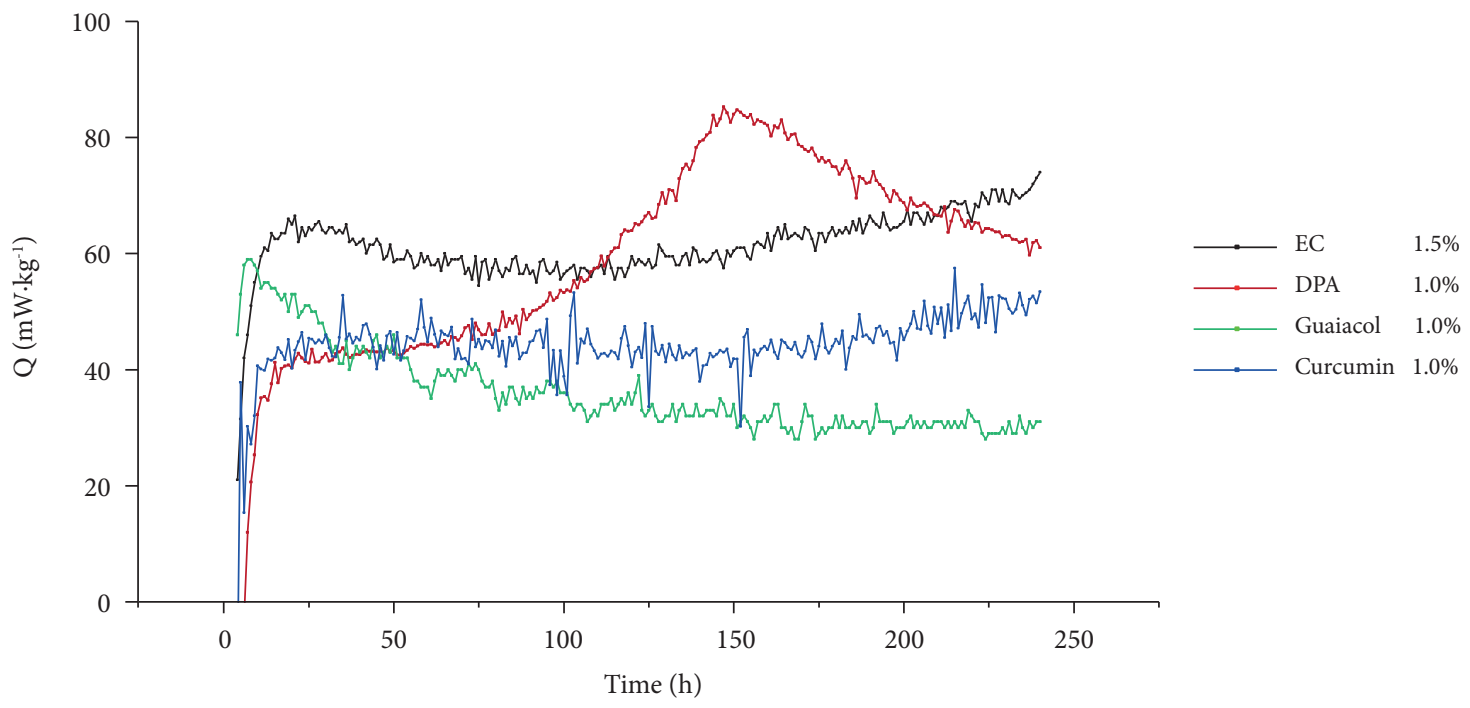

Figure 1. Comparison between new green and traditional stabilizers in the HFC.

Table 1. Prediction of carcinogenicity and mutagenicity of traditional and green stabilizers with different software tools.

\begin{tabular}{|c|c|c|c|c|}
\hline Software & VEGA & Toxtree & LAZAR & TEST \\
\hline \multirow{2}{*}{ DPA } & $\begin{array}{c}\text { Noncarcinogenic } \\
\text { Nonmutagenic }\end{array}$ & $\begin{array}{c}\text { Noncarcinogenic } \\
\text { Mutagenic }\end{array}$ & $\begin{array}{c}\text { Carcinogenic } \\
\text { Mutagenic }\end{array}$ & Nonmutagenic \\
\hline \multirow{2}{*}{ EC } & $\begin{array}{c}\text { Noncarcinogenic } \\
\text { Nonmutagenic }\end{array}$ & $\begin{array}{c}\text { Noncarcinogenic } \\
\text { Nonmutagenic }\end{array}$ & $\begin{array}{c}\text { Noncarcinogenic } \\
\text { Nonmutagenic }\end{array}$ & Nonmutagenic \\
\hline Curcumin & $\begin{array}{c}\text { Noncarcinogenic } \\
\text { Nonmutagenic }\end{array}$ & $\begin{array}{c}\text { Noncarcinogenic } \\
\text { Nonmutagenic }\end{array}$ & Carcinogenic & Nonmutagenic \\
\hline \multirow{2}{*}{ Guaiacol } & Carcinogenic & Noncarcinogenic & Nonmutagenic & Noncarcinogenic \\
& Nonmutagenic & Mutagenic & Nonmutagenic \\
\hline
\end{tabular}

\section{CONCLUSIONS}

The green stabilizers curcumin and guaiacol were successfully mixed with NC-based propellants. Results from HFC suggest that propellants with these stabilizers have a tendency to be more chemically stable when using the propellants stabilized with traditional DPA and EC as reference. Additional stability tests, NC molar mass degradation, and stabilizer depletion tests are now being performed for fully characterization of these propellants. The computational results suggested that the NC-based propellant stabilized with curcumin is nontoxic when compared to DPA and guaiacol. However, a toxicity investigation of their by-products after capturing nitrous groups during NC degradation is still necessary.

\section{AUTHORS' CONTRIBUTION}

Conceptualization, Rodrigues RLB and Mendonça Filho LG; Methodology, Rodrigues RLB and Mendonça Filho LG; Research, Rodrigues RLB; Writing - First version, Rodrigues RLB; Writing - Review \& Editing, Lemos MF; França TCC and Mendonça Filho LG; Resources, Mendonça Filho LG; Supervision, França TCC and Mendonça Filho LG. 


\section{REFERENCES}

[DQSO] Defense Quality and Standardzation Office (2010) Military standard propellants, solid: Sampling, examination and testing. Falls Church (USA): US Department of Defense.

[NATO] North Atlantic Council (2007) STANAG 4582 - Explosives, nitrocellulose-based propellants, stability test procedure and requirements using heat flow calorimetry. Brussels (Belgium): NATO.

Benfenati E, Manganaro A, Gini G (2013) VEGA-QSAR: Al inside a platform for predictive toxicology. CEUR Workshop Proc 1107:21-28.

Benigni R, Bossa C, Tcheremenskaia O (2013) Nongenotoxic carcinogenicity of chemicals: Mechanisms of action and early recognition through a new set of structural alerts. Chem Rev 113(5):2940-2957. https://doi.org/10.1021/cr300206t

Bohn MA (2009) Prediction of in-service time period of three differently stabilized single base propellants. Prop Explos Pyrotech 34(3):252266. https://doi.org/10.1002/prep.200900007

Cassano A, Manganaro A, Martin T, Young D, Piclin N, Pintore M, Bigoni D, Benfenati E (2010) CAESAR models for developmental toxicity. Chem Cent J 4(Suppl 4):1-11. https://doi.org/10.1186/1752-153X-4-S1-S4

Curtis NJ, Berry P (1989) Derivatives of ethyl centralite in Australian gun propellants. Prop Explos Pyrotech 14(6):260-265. https:// doi.org/10.1002/prep.19890140609

Dobson R, Dejeaifve A, Monseur L, Fonder N (2016) Novel stabilisers for nitrocellulose-based propellants. 7th Nitrocelluose Symposium.

Fligner MA, Verducci JS, Blower PE (2002) A modification of the Jaccard-Tanimoto similarity index for diverse selection of chemical compounds using binary strings. Technometrics 44(2):110-119. https: / doi.org/10.1198/004017002317375064

Hansen K, Mika S, Schroeter T, Sutter A, ter Laak A, Steger-Hartmann T, Heinrich N, Müller K-R (2009) Benchmark data set for in silico prediction of Ames mutagenicity. J Chem Inf Model 49(9):2077-2081. https://doi.org/10.1021/ci900161g

Helma C (2006) Lazy Structure-Activity Relationships (Lazar) for the prediction of rodent carcinogenicity and Salmonella mutagenicity. Mol Divers 10(2):147-158. https://doi.org/10.1007/s11030-005-9001-5

Helma C, Cramer T, Kramer S, De Raedt L (2004) Data mining and machine learning techniques for the identification of mutagenicity inducing substructures and structure activity relationships of noncongeneric compounds. J Chem Inf Comput Sci 44(4):1402-1411. https://doi.org/10.1021/ci034254q

Johnston BD, DeMaster EG (2003) Suppression of nitric oxide oxidation to nitrite by curcumin is due to the sequestration of the reaction intermediate nitrogen dioxide, not nitric oxide. Nitric Oxide 8(4):231-234. https://doi.org/10.1016/S1089-8603(03)00030-2

Krofli凶 A, Grilc M, Grgi凶 I (2015) Unraveling pathways of guaiacol nitration in atmospheric waters: Nitrite, a source of reactive nitronium ion in the atmosphere. Environ Sci Technol 49(15):9150-9158. https://doi.org/10.1021/acs.est.5b01811

Martin T (2016) User's guide for T.E.S.T. (Version 4.2) (Toxicity Estimation Software Tool) - A program to estimate toxicity from molecular structure. Washington (USA): US-EPA.

Muster W, Breidenbach A, Fischer H, Kirchner S, Müller L, Pähler A (2008) Computational toxicology in drug development. Drug Discov Today 13(7-8):303-310. https://doi.org/10.1016/j.drudis.2007.12.007

Patlewicz G, Jeliazkova N, Safford RJ, Worth AP, Aleksiev B (2008) Evaluation of the implementation of the Cramer classification scheme in the Toxtree software. SAR QSAR Environ Res 19(5-6):495-524. https://doi.org/10.1080/10629360802083871

Rodrigues RLB, Nichele J, França TCC, Mendonça Filho LG (2018) Predição de toxicidade dos estabilizantes usuais em propelentes à base de nitrocelulose e de seus principais produtos de degradação. Quím Nova 41(8):867-873. https://doi.org/10.21577/01004042.20170264

Vedani A, Dobler M, Hu Z, Smieško M (2015) OpenVirtualToxLab - A platform for generating and exchanging in silico toxicity data. Toxicol Lett 232(2):519-532. https://doi.org/10.1016/j.toxlet.2014.09.004 